\title{
Potential and Scope of Additive Manufacturing in Aerospace Industry with Reference to India
}

\author{
Vetrivel, P. Varun Teja, R. Sivaprakash, V. Vinay Krishnan, Vasanth
}

\begin{abstract}
Aerospace industry is one of the fastest growing industries in the world. Especially in India, it is estimated to grow in exponential rate owing to the rapid globalization and the fact that India is one of the world centres for tourism and trade. This exponential growth in the field of aerospace industry puts more demand on manufacturing and design of aircraft and its components. Unfortunately, the tradition method on spare parts production for aerospace industry cannot supply the growing demand to its fullest because it is time consuming and the cost of production is very high. Additive manufacturing, being one of the most revolutionary methods of is an appropriate substitute for the traditional manufacturing process in the aerospace industry as mass production becomes cheaper and save much of time. It also provides the flexibility to change the design and manufacturing method of any particular component with most ease at any stage from design to production. Additive manufacturing displays unarguable traits compared to traditional manufacturing in material saving, cost of production, requirement of skilled labour force and time consumption, especially in aerospace industry. However, there is not one single method of designing or producing the required component and this paper intends to classify and discuss each method in details and in comparison with each other. Few methods that are discussed in this paper include EBM, SLM, MD and LMD. In spite of the overwhelming advantage the technology has over the current method, it still faces few challenges to be fully implemented in floor level which is also focused in this paper in particular to India.
\end{abstract}

\section{INTRODUCTION}

THE birth of aerospace industry can be traced back to the invention of flight by the Wright brothers in 1903. As a result of two world wars and newer technologies, the field started gaining momentum and has grown to be one of the largest fields globally. New technologies like radar communication, gas engines, light weight combat vehicles came into picture during the second world war and ever since, the field of aerospace has been a major player in the development of a country, both in military and commercial use. From the late 20th century, aerospace has grown to an

Revised Version Manuscript Received on April 12, 2019.

Vetrivel, Assistant Professor, Department of Mechanical Engineering, SNS College of Technology, Coimbatore, Tamil Nadu. India (e-mail: vetri232@gmail.com)

P. Varun Teja, UG Student, Department of Mechanical Engineering, SNS College of Technology, Coimbatore, Tamil Nadu. India (e-mail: varunpteja@gmail.com)

R. Sivaprakash, UG Student, Department of Mechanical Engineering, SNS College of Technology, Coimbatore, Tamil Nadu. India (e-mail: sivaravi2529@gmail.com)

V. Vinay Krishnan, UG Student, Department of Mechanical Engineering, SNS College of Technology, Coimbatore, Tamil Nadu. India (e-mail: vinayvinu20000414@gmail.com)

Vasanth, UG Student, Department of Mechanical Engineering, SNS College of Technology, Coimbatore, Tamil Nadu. India

(e-mail: vasanththescientist@gmail.com) extent of including satellites, rockets and allied devices. As per reports more than 40 countries have strengthened their hold on the aerospace industry among which, America tops the list by employing at least $9,00,000$ people. The American company being is the world's largest producer of commercial and military air borne vehicles. The second largest employer state in the world next to America is the Europeans who have employed around 4,20,000 people. Few notable players in the field are airbus, Aerospatiale of France, daimler-benz, constructions aeronautics (CASA) of Spain. Te major fields in the aerospace industries include military, cargo, passenger and general aviation.

\section{ADDITIVE MANUFACTURING IN SUPPLY CHAIN}

It is expected to make a permanent mark and change the way that supply chain management is done I current trend. As the only requirements of additive manufacturing are a 3D cad model and raw materials, this would significantly affect the supply chain [12]. Though additive manufacturing is yet to produce mass scale production of components economically, it is expected to break this barrier in the new future. To facilitate this, a well guided study is required to find the suitable application. There are two different ways to link additive manufacturing with the aircraft spare parts industry. One being, producing the spare parts within the central plant itself which reduces the cost, time and resources incurred by the company [11]. This can also facilitate the moving of spare part from nearby plants instead of waiting for a part to come from a long distant supplier. The second method would be to have an AM facility in the vicinity of the service center itself as no transport from the main central station is needed. This can even more reduce the travel time and also completely eliminate the complications in inventory of the spare parts.

\section{OSPACE PARTS MANUFACTURING}

In Industrial 3D printing of high-tech aerospace components, it is cost-effective, with tool-less production of lightweight components which reduces fuel consumption, material costs and $\mathrm{CO} 2$ emissions Engine and turbine parts as well as cabin interior components. Functional components with complex geometries and defined aerodynamic properties can be manufactured quickly and cost-effectively with EOS technology. 
Fuel consumption and $\mathrm{CO} 2$ emissions were lowered with material and weight savings [1]. Manufacturer-specific changes and small scale production are in favour of Additive Manufacturing technology. This is why leading aerospace companies have integrated AM into their future planning of production strategies.

Cost reduction: Production costs are only incurred for the parts themselves, and doesn't cause setup and tooling costs at the time they are manufactured. Factors like small production cost doesn't add to the total cost incurred.. In addition, system parts that are designed can be realized as a single part, simplifying assembly and assuring quality [10].

Lightweight design: Intelligent lightweight structures manufactured using laser sintering processes combine high strength with a weight reduction of $40-60 \%$. The material savings result in more flexibility in design and engineering. This causes less emission and fuel consumption by the aircrafts.

Tool-less production: EOS industrial 3D printing technology enables maximum flexibility in production planning. In addition, tool less production processes require less energy and raw material than conventional manufacturing operations. Modified parts, upgrades and spare parts can be produced. Given the long service lives of airplanes, Additive Manufacturing processes yield clear cost benefits [3].

Some of the major players in the field of aerospace industry includes but are not limited to,

- Airnet Aviation Pvt Ltd.

- Bharat Dynamics Ltd.

- BrahMos Aerospace Private Ltd.

- Boeing International Corporation India Pvt Ltd.

- Electronics Corporation of India Ltd.

- Hindustan Aeronautics Ltd.

- $\quad$ Lockheed Martin India Pvt Ltd.

- Mahindra Defense Systems

\section{ADDITIVE MANUFACTURING}

Additive manufacturing describes processes in which the part to be produced is constructed by the addition of material. The construction is carried out in layers. The main aim of additive manufacture is layer by layer. AM takes production to the next level whereas conventional manufacturing techniques are capable of producing a wide range of shapes and designs.

One of the greatest benefits is the greater range of shapes which can be produced. Designs that can't be manufactured in one entire piece with traditional means can easily be achieved.

This has the advantage of being stronger; no weak spots which can be compromised or stressed.

The additive manufacturing process is very quick. With the assistance of the CAD software, making any changes takes simply the click of the mouse. Rapid prototyping consumes amazingly less time and completes the product in short span of time.

This not only provides flexibility, but also has the result of slashing costs too. In the past, the limitations of production have all too often influenced design, ruling out ideas because they weren't practically achievable. The introduction of this technology and its development made the process is simpler.

In traditional manufacturing methods a material is carved or shaped into the desired product by removing its parts in various ways.

Additive manufacturing is the pole opposite; structures are made by the addition of thousands of minuscule layers which combine to create the product. The process involves the use of a computer and special CAD software and it prints the desired shape. With a range of different materials, the cartridge is loaded with the relevant substance and this is "printed" into the shape, one wafer-thin layer at a time. These layers are repeatedly printed on top of each other and is fused together until the shape is complete.

\section{METHODOLOGIES IN ADDITIVE MANUFACTURING \& RESULTS}

\section{A. Selective Laser Melting (SLM)}

SLM is called as (Selective Laser Melting). SLM is in additive manufacturing method is specially developed for 3D printing metal alloys. It is the process of full melting process. Like in SLM process, it will be in layer by layer according to 3D model. It requires either argon or nitrogen at oxygen levels below 500 parts per million in order to create the perfect condition for melting [4]. The SLM processes are the same as other laser-based additive manufacturing technology. They may apply a layer of metal power, and then the laser will sinter the powder according to the 3D file, and applying a layer of metal power. Once if it is finished the metal needs to cool down before being extracted. Selective Laser Melting process uses supports in order to reinforce small angles and hangovers of the parts but also to stick the design to the job tray. The support will be removed manually after cooling. The SLM process is highly beneficial for the production of metal parts for prototyping. By this process the production can be quickly performed.

It allows to create complicated and highly detailed design that can't be done in any other technology, due to limitation of the traditional manufacturing process. With SLM it is possible to create thin-walled objects with intricate geometries. Customization and speeding time-to-market are also great benefits from the Selective Laser Melting technology. For the industrial use the process is still expensive and the part production is slow. 


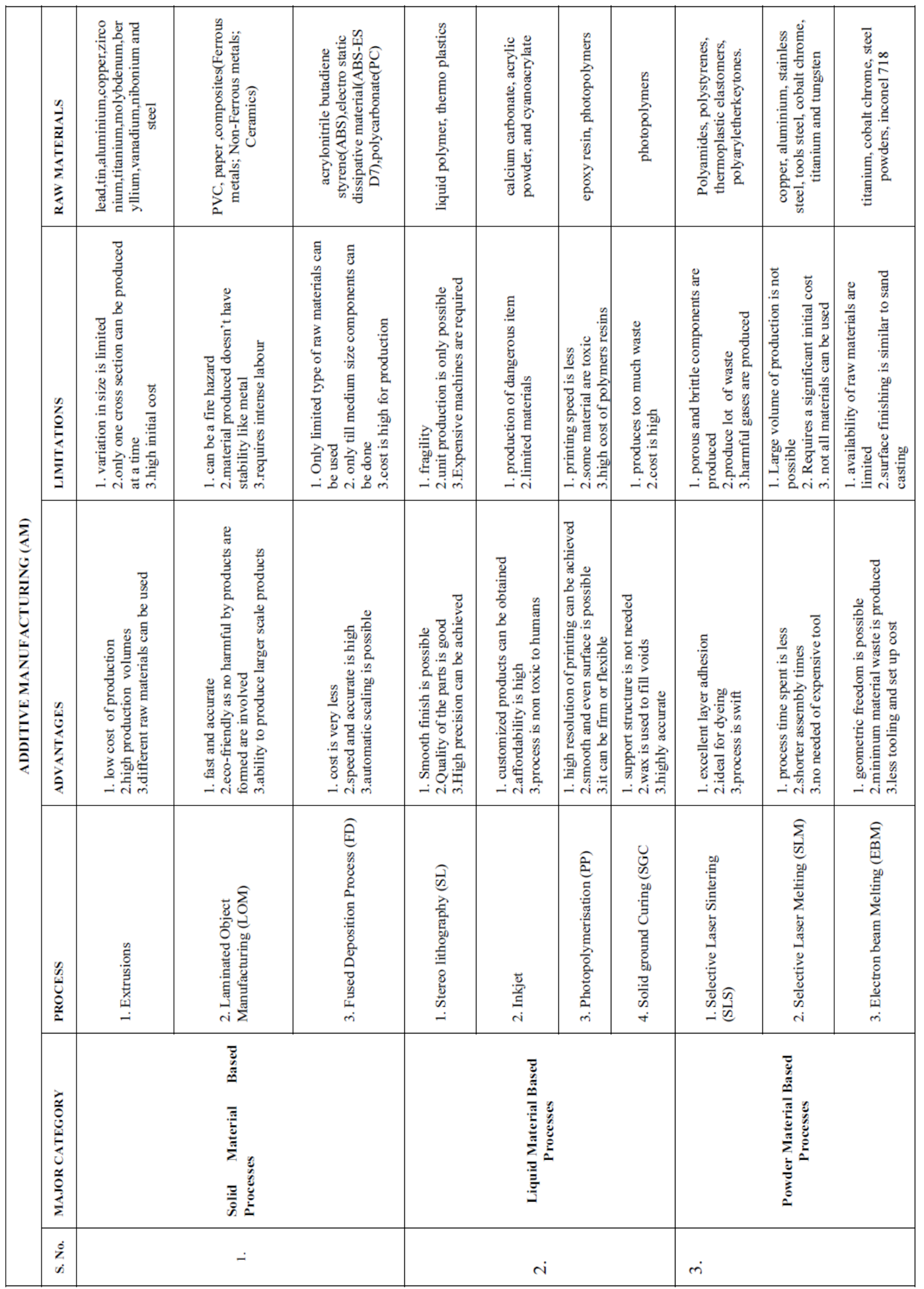

\section{B. Electron Beam Melting (EBM):}

Electron beam melting (EBM) is an innovative additive manufacturing $(\mathrm{AM})$ process in which metal powder or filament is completely melted by a concentrated beam of electrons. By the production the oxidation will not compromise highly reactive materials like titanium and the vacuum production is also required so electrons don't collide with gas molecules.

A tungsten filament in the electron beam gun is superheated to create a cloud of electrons that accelerate to approximately one-half the speed of light. 
A magnetic field focuses the beam to the desired diameter. A second magnetic field directs the beam of electrons to the desired spot on the print bed. Electron beam melting is a high-energy, high-temperature process.

Electron Beam Melting technology offers a competitive edge of progressive enterprises. It has many applications and the designers enjoy unparalleled design flexibility. EBM produces parts with similar properties to wrought parts and the cast parts. This process reduces the waste and inventory requirements. It satisfies the customer requirements and the build rates are often 3-5 times greater than AM technologies.

The surface of a parts printed with EBM requires postprocessing, while the smooth surfaces of DMDL produces parts doesn't needed a post-processing. This machine requires high maintenance, and this process requires a significant amount of validation. The validated supply chain is necessary to ensure the purity levels.

\section{Laser Metal Deposition (LMD)}

Laser metal deposition (LMD) is an additive manufacturing process in which a laser beam forms a melt pool on a metallic substrate, into which powder is fed.

The laser generates a weld pool on the surface of the existing components. A nozzle is used to add powder at the same time, which is melted on to produce the desired shape. The nozzle sprays the fine metal powder onto the base body. The laser beam comes from the center of the nozzle. The material that is applied can extend and growing in any direction

LMD enables higher build rate compared to other additive methods, which speeds up the process and it saves time. By the LMD process we can switch between different materials in additive manufacturing, several different powder containers can be active, which means alloys can also be formed. By the combination of materials we can create structures similar to sandwich design.

It is possible to build large components, since there is no need for a base chamber. LMD can be found in many industries, for example the aviation and aerospace, energy, petrochemical, automotive, and medical technology sectors. These material includes nickel based alloys such as INCONEL and HASTELLOY, cobalt based alloy such as Stellite, Carbides, stainless steel and titanium alloys [9].

\section{INFERENCE}

As far as materials are considered in additive manufacturing, polymers, metals, composites and ceramics are widely used. Nylon is one of the most commonly used polymer in additive manufacturing as it has a low melting point and good bonding strength when compare to other polymers. Metals are used either by melting it or bonding it in solid state. Powders of the metals are also used. Few of the ceramic materials used include alumina, silica and zirconia.

There are five major areas of AM related with value chain and they are: materials, system, software, application and production. The major drawback would be the not so large investment in the R\&D to currently make AM available to all the segments of industries rather than being with the few major players in the market.

As much as there are advantages to the budding technology, there are also few challenges to be met. Though $\mathrm{AM}$ was used for prototyping for a significant time period in industry, the stereotype of see the technology only for prototyping has not changed at large in the industrial mindset. It is not agreed or conceived that AM can be used for long time large scale manufacturing though it is currently used only for small scale manufacturing. Another concern would be the initial cost involved as it is high and the material cost is also fairly expensive. The newest problem that the technology faces is intellectual property right. Since AM is a multidisciplinary area, it is not east to train the required work force as it requires knowledge in all possible science background. It is not possible to expect a person to have all the required knowledge in the all the relevant fields.

\section{CONCLUSION}

1980s is the year that witnessed the rapid growth of additive manufacturing and is expected to be a $\$ 5.2$ billion capital field in 2020 [6]. Additive manufacturing has the ability to reduce the cost of production of any component in small scale. It consists of many processes within its domain to suite the requirement of a component. It is also safe to use and poses no threat to the working force physically. The main advantage is the use of a variety of materials for manufacturing and this makes it very attractive to the aerospace industry. It is estimated that the additive manufacturing will increase to over $\$ 1$ billion by 2025 says a by NERAC in 2013. Most of the aerospace industries are after this technology as many of their components are relatively complicated and are needed in very small numbers. AM typically suites this requirement as it produces minimal components of even complex geometries.

Even materials which are expensive and complicated to manufacture like alloys of titanium, nickel and special types of steels can be used by AM. Since AM make the component through step by step layer formation, the cost and time of manufacturing using even a hard and expensive material can be made manageable.

\section{REFERENCES}

1. Peng Liu et al., "The Impact of Additive Manufacturing in the Aircraft Spare Parts Supply Chain: Supply Chain Operation Reference (scor) Model based Analysis" Production Planning and Control, Taylor \& francis, 2013.

2. Adrian Uriondo et al., "The present and future of additive manufacturing in the aerospace sector: the review of important aspects" 2015.

3. "3D printing in aerospace and its long-term sustainability" virtual and physical Prototyping, Taylor \& francis, 2015. 
4. A.A. Shapiro et al., "Additive manufacturing for aerospace flight applications" journal of spacecraft and rockets, 2016.

5. Kaufui V. Wong et al., "A review of additive manufacturing" International scholarly research network, 2012.

6. Yong Huang et al., “Additive manufacturing: current state, future potential gaps and needs and recommendation", 2014.

7. Daniel-Alexandar Turk et al., "Additive manufacturing with composits for integrated aircraft structures", 2016.

8. Huang, Y., Leu, M.C.,, Mazmunder, J., \& Donmez, A. "Additive Manufacturing: Current Sate, Future Potential, Gaps, Needs, and Recommendations." Journal of Manufacturing Science and Engineering 2015.

9. R. Hague. "Sustainability of Additive Manufacturing: Measuring the Energy Consumption of the Laser Sintering Process." Proceedings of the Institution of Mechanical Engineers, 2011.

10. Hasan, S., and A. E. W. Rennie. "The Application of Rapid Manufacturing Technologies in the Spare Parts Industry." 2008.

11. Holmstrom, J., J. Partanen, J. Tuomi, and M. Walter. "Rapid Manufacturing in the Spare Parts Supply Chain: Alternative Approaches to Capacity Deployment." Journal of Manufacturing Technology Management 2010.

12. Huang, S. H., S. K. Sheoran, and H. Keskar. "Computer assisted Supply Chain Configuration Based on Supply Chain Operations Reference (SCOR) Model." Computers \&Industrial Engineering, 2005. 